\title{
NOTAS PARA A HISTÓRIA DA ANTROPOLOGIA NO RIO GRANDE DO SUL (1940-1969)
}

\author{
Bernardo Lewgoy \\ Eduardo Bettiol Prado* \\ Universidade Federal do Rio Grande do Sul - Brasil
}

Resumo: Este artigo discute a trajetória acadêmica da Antropologia no Rio Grande do Sul, Brasil, no período que vai de 1940 a 1969, Iniciada pelo padre Balduíno Rambo, botânico, teólogo e líder jesuíta local, a Antropologia no Rio Grande do Sul vai progressivamente transformando-se, de uma ênfase majoritária em arqueologia (inicialmente no molde "hard science") para o perfil diversificado que a caracteriza a partir dos anos 70.

Abstract: The purpose of the present paper is to develop the academic history of Anthropology in Rio Grande do Sul, Brazil, from 1940 to 1969, Started by father Balduíno Rambo, a botanic, theologist and remarkable Jesuit leader, the beginning Anthropology worked only in archeological studies, situation that remained unchanged until the sixties. From 1970, the Anthropology of Rio Grande do Sul will have a new profile, having his major emphasis in simbolic and cultured studies.

\section{Introdução}

Este texto versa sobre a história da Antropologia no Rio Grande do Sul, tomando como fio condutor a trajetória desta disciplina na UFRGS, no período que vai do início da década de 1940, época da sua criação, até fins dos anos 60, quando ocorre a Reforma do Ensino no regime militar. O material pesquisado cinge-se a documentos, publicações, cadernos de aula e depoimentos colhidos com antigos professores, informantes-chave

\footnotetext{
* Bolsista de iniciação científica do CNPq.
} 
desta investigação. ${ }^{1}$ Propomo-nos a descrever as linhas gerais da formação de um espaço acadêmico da Antropologia no Rio Grande do Sul, localizado não apenas na UFRGS mas principalmente nesta universidade. É certo que a UFRGS não concentrou toda a pesquisa, discussão ou ensino da Antropologia no Rio Grande, mas não é menos certo que os caminhos que levaram à institucionalização desta disciplina no estado estão intimamente vinculados à história desta universidade, a projetos pessoais e coletivos nela investidos e ao próprio ritmo de diferenciação e autonomização das ciências humanas em relação às ciências naturais neste espaço acadêmico.

Neste sentido, a idéia de um resgate da memória da Antropologia, ainda que desprovido da pretensão de esgotar o assunto, talvez traduza melhor o intuito que vem animando esta pesquisa. A palavra "resgate" evoca o movimento de tornar público algo que o tempo vinha relegando ao terreno do informal e do privado, às conversas com os professores veteranos no café e na pausa das aulas, acessível não enquanto sistemática de investigação científica mas apenas no investimento lúdico que caracteriza a sociabilidade desinteressada dos intervalos, divertida mas fugaz e destinada a um público muito restrito. É claro que este resgate da memória do cativeiro da informalidade para um circuito público é inevitavelmente atravessado por uma transformação no registro do interesse por mediações de múltiplas ordens, por recortes seletivos e interpretações governadas por reduções empobrecedoras, e até mesmo por inevitáveis anacronismos, projeções retrospectivas de padrões e critérios científicos a um passado cujos atores talvez entendessem "Antropologia” de um modo bastante diferenciado do nosso.

\section{Padre Balduíno Rambo: o pioneiro na paróquia}

Como afirmávamos não é possível projetar retrospectivamente nossa compreensão atual de "Antropologia” para o que seus praticantes concebiam e vivenciavam e na UFRGS das décadas de 40, 50 e 60 ainda que a

\footnotetext{
A pesquisa sobre história da Antropologia no Rio Grande do Sul foi inicialmente coordenada pelo professor Ruben Oliven, a quem agradecemos pelo decisivo apoio. Utilizamos também um texto preliminar escrito sobre o assunto "História da Antropologia no Rio Grande do Sul”, das pesquisadoras Sitiara Robin e Lúcia Muller. o qual não foi publicado. Queremos registrar que parte do material pesquisado, assim como algumas entrevistas, foram realizadas por estas pesquisadoras, que nos antecederam, e a quem cabe parte dos créditos pelos resultados da pesquisa.
}

Horizontes Antropológicos, Porto Alegre, ano 3, n. 7, p. 239-251, nov. 1997 
descontinuidade não chegue às raias do incomensurável, se tomarmos como parâmetro a dinâmica produção de outros centros no Brasil e no mundo. Isto deve-se não apenas às influências escolares que tendemos a considerar determinantes em cada época, mas às vezes, devido a fatores mais singelos, como o grau de isolamento de nossa província acadêmica face aos principais centros ou mesmo a origem, formação, trajetória social e acadêmica de seus praticantes, marcados na época por um notável autodidatismo, erudição difusa e pela influência de uma intelectualidade jesuítica emergente a qual, já atuante em outros setores da vida intelectual e política do Rio Grande do Sul passa a ganhar expressão restrita na UFRGS das décadas de 30 e $40 .^{2}$

As circunstâncias particulares em que surgia a disciplina de Antropologia e Etnologia da UFRGS permitem qualificá-la (em seu início ainda ligada ao curso de História e Geografia) como veiculadora de uma concepção humanista, complementar e formalmente integradora do conteúdo de outras disciplinas, uma espécie de imagem ornamental de homem, condizente com as expectativas de então. A criação da cadeira de Antropologia e Etnologia da URGS - na época universidade estadual não escaparia aos elos de troca entre as diferentes facções das elites políticas e seus clientes intelectuais, as quais costuravam redes informais de influência e prestígio que ganhavam expressão na indicação de professores para disciplinas, configurando em cada caso uma disputa entre as facções políticas, intelectuais ou eclesiásticas que apoiavam os candidatos. A Faculdade de Filosofia da URGS, formada na década de 40, agrupando desde as ciências humanas até as ciências naturais, teve em sua origem a marca da influência de uma intelectualidade ligada direta ou indiretamente ao establishment católico do estado, a qual se fez sentir até a década de 60, como no episódio em que Jean-Paul Sartre fora impedido de ministrar uma conferência na UFRGS por suas posições ateístas e anticlericais. A cátedra de Antropologia e Etnologia, criada em 1942, também fora concedida a um padre jesuíta, Balduíno Rambo, mas através de um jogo de pressões. Rambo, intelectual polivalente, poeta, líder popular na colônia alemã e também um notável naturalista, postulava a cátedra de Botânica no que encontrava a disputa de Alarich Schültz, também

\footnotetext{
2 A grande influência dos setores católicos na sociedade gaúcha da primeira metade do século vieram a influir na formação da nascente Faculdade de Filosofia, como mostram os textos do volume de Hessel e Moreira (1967).
} 
um consagrado taxinomista. ${ }^{3}$ Tendo Schültz vencido a disputa e seria interessante saber com que precisão os grupos que a cada um apoiavam Rambo foi presenteado com a cátedra de Antropologia e Etnologia como um premio de consolação, provavelmente para acomodar possíveis descontentamentos com o setor da hierarquia católica que o apoiava, concedendo espaço e reconhecimento aos jesuítas que nele se viam representados. ${ }^{4}$

A novidade desta disciplina associada aos múltiplos interesses do padre Rambo, sua atenção primordial por botânica, seu ingresso inesperado na Antropologia e a inexistência de uma tradição acumulada de trabalho científico nesta área, caracterizaram este encontro de um cientista autodidata com um terreno virgem em estudos etnológicos e baliza algo do desenvolvimento desta disciplina até pelo menos o ingresso de seu discípulo, o padre jesuíta e futuro arqueólogo Pedro Ignácio Schmitz, em 1958, quando uma nova fase se abrirá para a Antropologia da UFRGS.

Não que inexistissem precursores ou contemporâneos. Já na primeira metade do século XIX o belga Mabilde havia feito estudos entre os Kaigangues do RS, analisando sua medicina nativa, remédios e contraceptivos, mas seu pioneirismo é tido como uma influência isolada e sem continuadores. Também não imprimiram marcas imediatas sobre a emergente disciplina na UFRGS as visitas ao Rio Grande do Sul de Roger Bastide, Melville Herskovits e Emílio Willems, nas décadas de 40 e 50, ainda que estes autores tenham escrito textos circunstanciais mas significativos sobre aspectos etnológicos do Rio Grande do Sul. ${ }^{5}$

\footnotetext{
3 A carreira do padre Rambo iniciou-se no Colégio Catarinense em Florianópolis, SC, no ano de 1927. Lá ele ministrou aulas de francês, aritmética e desenho. Em 1928 Rambo interrompe o seu trabalho para cursar Filosofia em Pullach, Alemanha. Ao retornar ao Brasil, em 1931, Rambo retoma a carreira do magistério dando aulas no Colégio Anchieta. Neste período deu aulas de história natural, física e cosmologia. Isto durou até o ano de 1934 quando Rambo decidiu-se por completar a sua formação sacerdotal em São Leopoldo. Tendo terminado o curso de teologia em 1938. Rambo retorna para Porto Alegre, onde permanece dando aulas no Colégio Anchieta até o fim de sua vida. A partir de 1941 Rambo passa a conjugar as aulas no Colégio Anchieta com a sua nova função de catedrático fundador da cadeira de Antropologia e Etnologia da Faculdade de Filosofia, Ciências e Letras da UFRGS. Em 1947 exerce atividade de "prefeito de estudos" do Colégio Anchieta e, em 1955 passa a dirigir o Museu de Ciências Naturais da secretaria estadual da educação e cultura, além de lecionar Antropologia Cultural na faculdade de Medicina da UFRGS. Por fim, em 1956, juntamente com outros colegas jesuítas, funda o Instituto Anchietano de pesquisas que vem a tornar-se um importante centro de conhecimento.

4 Depoimento do professor Brochado.

5 Ver referências bibliográficas.
} 
Também o fraco ou inexistente intercâmbio com centros mais integrados à produção antropológica mundial, como a USP, o Museu Paulista e o Museu Nacional permite-nos aferir o descompasso e o paroquialismo que caracterizam os primórdios da Antropologia na UFRGS nas décadas de 40 e 50 . A ausência de uma concepção integrada de ensino e pesquisa, à época, é complementada pelo modo como eram ministradas as aulas, qualificadas nos depoimentos como "magistrais", às quais correspondiam um certo modelo de erudição e retórica, cuja inspiração era buscada nas aulas das Faculdades de Direito e de Medicina:

Balduíno Rambo foi o fundador da Antropologia e ele dava a aula magistral e utilizava, textos que ele mesmo preparava, que era popularmente chamada de "sebenta”, que era mimeografada. Então as aulas do padre Rambo eram as aulas - ele era muito acatado como cientista. Ele lia a aula e fazia uma pausa a cada cinco minutos e perguntava: “alguma dúvida?” - com sotaque alemão. Em geral não havia dúvida. Aí lia e era sempre a mesma coisa... (Sérgio Teixeira).

O tipo de Antropologia ministrado nessas aulas revelava a influência cruzada da ênfase "humanista cristã" com a formação de naturalista do padre Rambo, preocupado com a "evolução do homem" em que a "evolução do homem brasileiro" figurava como uma ramificação - daí a preocupação com dados esparsos recolhidos em artigos sobre grupos indígenas brasileiros. Esta mescla de Antropologia física com uma preocupação evolucionista foi aproximando o padre Rambo da arqueologia, encontrando um certo suporte teórico e guarida nos trabalhos da escola histórico-cultural do padre Wilhelm Schmidt, de Viena. Não é difícil supor que tal estofo escolar funcionou como um relé que permitia integrar a formação de cientista natural, humanista e encarregado da disciplina de Antropologia e Etnologia da UFRGS.

Não nos parece também que a preocupação do padre Rambo com a valorização da etnia alemã no Rio Grande do Sul - de que era originário encontrasse incidências diretas ou fornecesse um certo suporte mesmo que oblíquo, à sua dedicação tópica à Antropologia. Isto só teria sido possível se Rambo tivesse se familiarizado com a Antropologia pós-boasiana. Mesmo que Rambo tivesse notícia da orientação culturalista americana, não era este o conteúdo trabalhado em suas aulas. Sua imagem de Antropologia estava colada às ciências naturais, desembocando naturalmente no estímulo à pesquisa arqueológica por seus alunos. 
No entanto, mesmo marcado pelo autodidatismo, pelo encontro insólito com uma disciplina científica pouco afeita aos seus principais interesses, pelo ambiente provinciano da UFRGS e por sua dispersão em diversas atividades heterogêneas, ainda assim Rambo pode envidar alguns esforços especificamente científicos no campo da etnologia e da arqueologia, fazendo uma incursão de estudos aos Kaigangues e publicando os primeiros dados arqueológicos sobre o Rio Grande do Sul, na década de 50. Além disso suas atividades de naturalista e atuação junto à intelectualidade jesuítica levaram-no à fundação do Instituto Anchietano, em São Leopoldo (1956), no que pode ser considerado um decisivo incentivador da Botânica e da Arqueologia no Rio Grande do Sul. Neste instituto, concebido ao modo dos grandes museus científicos, Rambo encontrou a autonomia e o espaço para a produção científica que não encontrava na UFRGS, reunindo uma equipe de pesquisadores sob sua direção, armazenando seu famoso herbarium com mais de oitenta mil exemplares e constituindo o embrião do que viria a ser um dos mais notáveis espaços da arqueologia do Brasil.

\section{Tupi or not tupi: a segunda geração de antropólogos na UFRGS}

Em 1956 começa a despontar uma nova geração na Antropologia na UFRGS. A disciplina de língua Tupi passa a ser ministrada no curso de Geografia e História, sendo tida como responsabilidade da Antropologia. Este interesse pela língua Tupi, imposto mais como prolongamento de uma corrente de pensamento nacionalista ligada aos círculos nacionais de poder do que propriamente como uma exigência intrínseca da incipiente comunidade de antropólogos locais, representava um eco distante de um movimento de intelectuais brasileiros que deita suas raízes no romantismo oitocentista, originado "numa tendência que procurava valorizar ao máximo os reduzidos rastros lexicais deixados pelas línguas indígenas na língua brasileira” (Gnerre, 1991, p. 18). O ensino de Tupi na UFRGS, introduzido na década de 50 por inspiração do professor Alejandro Ortigoza, restringia-se ao ensino de topônimos, tendo sido também ministrado pelo professor Pedro Ignácio Schmitz.

A disciplina de Antropologia Física foi inicialmente ministrada pelo professor Petrucci, médico de filiação científica positivista - ainda que não ficasse bem claro a acepção precisa que este equívoco termo guardava para este professor. Suas aulas circunscreviam-se ao exame de crânios e ossos, mais ao 
gosto de uma antropometria inspirada por considerações da medicina legal do que propriamente incorporando os avanços da genética ou da paleontologia. Ambas as disciplinas tiveram vida curta na UFRGS, vindo a desaparecer na década de 60, mas serviram, mesmo assim, para uma ampliação do espaço acadêmico da Antropologia nesta universidade. Também são do final da década de 50 as primeiras publicações de trabalhos antropológicos na extinta revista Organom, da Faculdade de Filosofia, Ciências e Letras da UFRGS, versando sobre etnologia e arqueologia das antigas culturas indígenas sul-riograndenses, onde assinaram artigos Balduíno Rambo, Pedro Ignácio Schmitz e Dorival Schmitz. ${ }^{6}$ A revista Organom formada sob a inspiração dos professores do curso de Filosofia, era aberta à contribuição de textos científicos e de crítica literária de diversas vertentes, sendo assim fiel à estruturação acadêmica da polivalente Faculdade de Filosofia Ciências e Letras da UFRGS. Ainda imperava o autodidatismo, no sentido do então baixo índice de troca com outros centros de pesquisa, mas já se esboçava um espaço para o escoamento da nascente produção antropológica da UFRGS. Apenas não era possível temperar a reflexão com a experiência cosmopolita de integração generalizante dos dados locais, o que só viria a ocorrer nas décadas seguintes. Somente nos anos sessenta os professores de antropologia começam a sair para os cursos de especialização ou pós-graduação em outras universidades.

Ainda nesta época (final da década de 50) verifica-se uma decisiva mudança para a Antropologia da UFRGS. Trata-se da entrada do professor Pedro Ignácio Schmitz como professor colaborador na cátedra de Antropologia e Etnografia do Brasil. Schmitz, padre jesuíta e discípulo de Rambo, formado em História e Geografia em 1958, sucedeu a Rambo não apenas na UFRGS, mas também na condução do Instituto Anchietano, vindo a tornar-se um dos mais importantes arqueólogos do Brasil $\mathrm{O}$ apadrinhamento de Schmitz por Rambo extravasava em muito uma mera relação profissional dentro da Universidade, ou fraternal dentro da ordem jesuítica. Rambo elegeu Schmitz como seu filho e sucessor. Tendo inicialmente entrado na UFRGS por incentivo do padre e historiador jesuíta Luiz Gonzaga Jaeger (de quem era secretário), que pensava em fazê-lo seu herdeiro nesta função, Schmitz logo se tornou um discípulo de Rambo, com quem constantemente viajava em incursões botânicas ou arqueológicas. Pelo decisivo apoio de Rambo, Schmitz

6 Cf. o número 2, de abril de 1959, da revista Organom, Porto Alegre, Faculdade de Filosofia da UFRGS. 
foi estudar no Paraguai e na Argentina, onde incrementou sua formação de arqueólogo, no início dos anos $60 .^{7}$

Como já foi dito anteriormente até a entrada de Schmitz a cátedra de Antropologia seguia os caminhos da escola histórico-cultural de Viena. O padre Schmitz introduziu a orientação culturalista norte-americana na leitura e formação dos alunos da cátedra de Antropologia, além de iniciar uma longa carreira de pesquisas arqueológicas junto com seus discípulos.

O esforço demonstrado por Schmitz (e por aqueles que após ele ingressaram na Antropologia) foram significativos no sentido de modernizar a ciência antropológica na UFRGS de então. Como os próprios entrevistados afirmam este é um período marcado pelas mudanças e pelo espírito empreendedor. As sebentas, espécie de "livro de estudos” escrito e mimeografado pelos professores (com base em leituras anteriormente feitas), foram sendo substituídas por livros como, por exemplo, o "Antropologia Cultural”, de Félix Keesing.

Outro aspecto relevante consiste nas contratações de professores para a Antropologia. Não havia contratação por concurso (prática muito recente, na verdade). O que ocorria era o apadrinhamento de determinados alunos pelos catedráticos. E claro que tal prática trazia consigo a ambigüidade. Os professores procuravam indicar aqueles alunos com os quais tinham maior afinidade intelectual, mantendo uma mesma linha de pensamento e pesquisa. Através de Rambo e Schmitz ingressaram na UFRGS o professor Artur Blásio Rambo, irmão do professor Balduíno Rambo, o professor Sérgio Alves Teixeira e o professor José Joaquim Justiniano Proença Brochado.

Nota-se que até a entrada de Artur Rambo a influência da tradição jesuítica continua forte. Balduíno Rambo tinha Schmitz em alta estima e o considerava seu "filho intelectual” e sucessor. Artur Rambo, apesar de inicialmente não estar ligado a área de Antropologia, acaba sendo convencido pelo irmão, principalmente por uma diferença, na sua percepção, que se colocava como divisora de águas entre a cátedra de Antropologia e as demais cátedras da UFRGS: a não interferência do catedrático nas aulas de seus auxiliares:

Eu tinha sido convidado para trabalhar na Geologia, mas eu não gostei do ambiente. O pessoal lá, tinha certas pessoas que mandavam lá dentro, não

\footnotetext{
7 Ver a este respeito Schmitz (1997).
} 
gostava do ambiente, não tinha liberdade. Aqui eu tinha toda a liberdade... e o Balduíno me deu no primeiro dia e disse: olha, faz o teu programa, depois tu pega as tuas aulas e eu não vou entrar nunca na tua sala de aula pra fazer...

Esta autonomia dada pelo professor Rambo aos seus auxiliares permitiu uma maior abertura às experimentações de novos temas e influências na Antropologia na UFRGS, a qual desembocaria nas pesquisas arqueológicas de Schmitz e Brochado, na década de 60.

Mesmo transformado, o ambiente acadêmico do início dos anos 60 ainda ostentava traços provincianos. A quase inexistência de intercâmbios de conhecimento com outros centros obrigava os novos antropólogos a seguirem a trilha do autodidatismo. Schmitz preocupou-se com a reconstituição histórica do Rio Grande do Sul anterior à chegada dos colonizadores europeus, associando-se ao jovem professor José Brochado. Artur Rambo dedicou-se a pesquisar outro tronco constitutivo do Rio Grande do Sul e que confundia-se com suas origens familiares: a colonização alemã. A Antropologia na UFRGS, na década de 60 pode ser caracterizada pelo predomínio dos arqueólogos, traço que só se modificará pela recomposição promovida pelo professor Sérgio Teixeira na década seguinte. Preocupado com a Antropologia de grupos do presente, Teixeira desempenhou um importante papel na reorientação das preocupações da área, influindo para o ingresso de profissionais com preocupações afins, como Ruben George Oliven, nos anos 70.

Nos anos 60 as Ciências Sociais do Rio Grande do Sul estão marcadas pela progressiva adesão dos profissionais a modelos teóricos e políticos oriundos da matriz marxista. Isto acarretou implicações políticas desfavoráveis para a imagem da Antropologia da época. Ora preocupada ora com o estudo da evolução sócio-cultural, ora com o seu horizonte voltado para grupos indígenas ou minorias étnicas, a Antropologia local não se associava nem teórica nem politicamente ao movimento de rebeldia que passou a inquietar as Ciências Sociais, sendo ainda suspeita de "funcionalismo" ou estigmatizada como "servil ao imperialismo” entre alguns dos pares acadêmicos e alunos de outras disciplinas. Por parte dos alunos a imagem da Antropologia não era muito boa. Sabe-se que a década de 60 foi um período áureo para o movimento estudantil universitário. Sendo um ambiente notadamente avesso as correntes teóricas não-marxistas os professores de Antropologia sofriam algumas restrições em suas aulas. E por parte do corpo docente da UFRGS haviam outros problemas 
relacionados às disputas internas a universidade. Assim, questões como distribuição de verbas, vagas para contratação de novos professores, espaço físico dentro da universidade eram importantes pontos de controvérsia na política acadêmica (como são até hoje). A força política do grupo da Antropologia via-se reduzida em função desses fatores:

E claro, naquela época eu era um entusiasta cia Antropologia americana, da Antropologia Geral das Ciências Sociais. Hoje eu já não acredito mais nada disso. Eu acreditava naquelas coisas, Que aquilo podia reformar o mundo, não é?...e inclusive às vezes tinha muitos alunos na década de 60 e tantos, no tempo dos militares, tinha às vezes bastante atrito com os alunos porque os alunos porque os alunos eram marxistas. (José Brochado).

Na década de 60 e também 70, as Ciências Sociais da moda no Brasil ou em evidência era a Sociologia em primeiríssimo plano, a Política num plano inferior ao da Sociologia e a Antropologia inferior as duas. Então quer dizer um marxismo triunfante... a Antropologia não tratava de luta de classes, nem da manutenção e conquista de poder, mas tratava dessas coisas menores da cultura, do simbolismo, Antropologia não tinha vez... então a Antropologia ficava em situação periférica, e a gente sentia isso por parte de alunos e professores. (Sérgio Teixeira).

Com a entrada do professor José Brochado na área de Antropologia, as pesquisas em Arqueologia ganharam novo fôlego. Tendo em vista seu interesse comum por Arqueologia, Schmitz indica Brochado como auxiliar de ensino na cátedra (com a morte de Balduíno Rambo em 1961, Schmitz assume a regência da cátedra). A inteligência e a juventude do professor Brochado estimularam Schmitz a voltar-se para a pesquisa em Arqueologia, coisa que não fazia há alguns anos. Num primeiro momento realizaram pesquisas em Torres e Rio Grande (vestígios dos grupos guarani e minuano), isto tudo sem praticamente nenhum auxílio financeiro, nem por parte da universidade nem dos órgãos de fomento a pesquisa.

Este quadro de relativo isolamento político e institucional, aliado à quase inexistência de canais de troca de conhecimento com outros centros de saber, começa a mudar a partir do início do PRONAPA - Programa Nacional de Auxílio às Pesquisas Arqueológicas. O PRONAPA iniciou em 1966 e durou até o ano de 1970. Era uma iniciativa do Smithsonian Institute, um órgão 
privado norte-americano de fomento a pesquisa e que, conveniado ao governo brasileiro, patrocinou a pesquisa em Arqueologia durante este qüinqüênio. Com o PRONAPA, os arqueólogos da UFRGS associam sua pesquisa e discussões a uma primeira tentativa de intercâmbio com profissionais de projeção nacional e internacional, como os arqueólogos americanos Betty Megers e Clifford Evans. A máxima "é preciso ser reconhecido lá fora antes de fazer sucesso aqui” caiu como uma luva para tal situação. Com o aval de um instituto de pesquisas como o Smithsonian, a Antropologia local passa a desfrutar de uma maior reputação acadêmica, além de começar a contar com um importante apoio material para a pesquisa. As verbas não se comparavam às destinadas a outras áreas de conhecimento, mas vinham. Além disso, o PRONAPA permitiu que os arqueólogos brasileiros viessem a se conhecer melhor, iniciando ou estreitando laços que se mostrariam estratégicos num futuro próximo.

O objetivo primário de criar espaços para a pesquisa arqueológica no Brasil foi alcançados pelo PRONAPA. O mesmo não pode ser dito em relação à criação de uma rede de intercâmbio internacional, bem como aos conhecimentos transmitidos pelos pesquisadores norte-americanos (Betty Meggers e Clifford Evans), em sua estada por aqui. Pelos depoimentos de nossos informantes, percebemos que os ensinamentos passados pelos representantes do Smithsonian resumiram-se a técnicas de coleta e interpretação de dados, tendo sido desprezados deste intercâmbio a oferta global de orientações teórico-metodológicas bem como o espectro de problemáticas de pesquisa disponíveis nos EUA à época

Nós tivemos sorte de vir alguém aqui e dizer que havia Arqueologia no Brasil, que se justificava fazer Arqueologia. Como era estrangeiro e era o Smithsonian, tem muito prestígio científico, o governo achou: Bah, vai ver que é verdade, tem Arqueologia. Mas a Betty Megers e o Clifford Evans não nos deram instruções nenhuma de como fazer Arqueologia, nem eles sabiam o que fazer aqui no sul do Brasil. Não tinham idéia nenhuma. Eles só estavam juntando dados em vista de um objetivo maior. Eu até hoje fico pensando, isso foi muito ruim... eles tinham idéias muito... só faziam determinado tipo de trabalho e não nos explicavam nada, eles não explicavam absolutamente nada... (José Brochado).

Imensas lacunas foram deixadas. Restou o saldo positivo de contatos iniciais entre os arqueólogos brasileiros, o que veio a se generalizar com a consolidação posterior de sua organização em nível nacional. 


\section{Conclusão}

Iniciada com o ingresso do padre Balduíno Rambo, notável botânico e literato, mas não antropólogo no sentido em que hoje concebemos a profissão, a Antropologia na UFRGS durante as décadas de 40 e 50, acompanhou o perfil provinciano desta universidade. Este quadro só viria a transformar-se na década de 60, a partir da influência do padre Pedro Inácio Schmitz, que daria um decisivo ímpeto a pesquisa arqueológica, e à participação dos arqueólogos da UFRGS no PRONAPA, do qual só viriam a colher frutos posteriores e indiretos. O que modernamente entendemos por Antropologia, disciplina voltada para a compreensão dos sistemas simbólicos e mecanismos sociológicos que presidem à cultura dos grupos humanos, só começou a ser introduzido, de um lado, pela leitura de alguns manuais acadêmicos americanos e, por outro, pelas preocupações de pesquisa dos professores Artur Blásio Rambo e Sérgio Teixeira. Somente na década de 70 a Antropologia da UFRGS consolida-se como um espaço de pesquisa dotado de um pós-graduação ou seja, praticamente na terceira geração de antropólogos a partir de Rambo.

\section{Referências}

ARAÚJO, A. As duas epistemes de Balduíno Rambo. Episteme, Porto Alegre: Instituto Latino Americano de Estudos Avançados/UFRGS, v. 2, n. 3, 1997.

BASTIDE, R. In: BASTIDE, R. Sociologia do folclore brasileiro. São Paulo: Anhembi, 1959.

FARIA, L. de C. Antropologia: espetáculo e excelência. Rio de Janeiro: Editora da UFRJ, 1994.

GNERRE, M. Linguagem, escrita e poder. São Paulo: Martins Fontes, 1991.

HERSKOVITS, M. Deuses africanos em Porto Alegre. Província de São Pedro, n. 11, mar./jun. 1948.

HESSEL, L. F.; MOREIRA, E. D. M. (Org.). Vinte e cinco anos da Faculdade de Filosofia. Porto Alegre: Editora da UFRGS, 1967. 
MABILDE, A. Correspondência oficial com o governo da Província do Rio Grande do Sul: cartas de 13-03-1850. Porto Alegre: Arquivo Público do Estado do Rio Grande do Sul, 1848-1850.

MABILDE, A. Apontamentos sobre os indígenas selvagens da nação “coroados" que habitam os sertões do Rio Grande do Sul. Annuario do Estado do Rio Grande do Sul, Porto Alegre, anno 13, p. 145-167, 1897.

MABILDE, A. Apontamentos sobre os indígenas selvagens da nação "coroados" que habitam os sertões do Rio Grande do Sul. Annuario do Estado do Rio Grande do Sul, Porto Alegre, anno 15, p. 125-151, 1899.

RABUSKE, A. Balduíno Rambo, S. J. Sacerdote, naturalista, escritor e líder popular. Revista Pesquisas em História, São Leopoldo: Instituto Anchietano de Pesquisas, n. 26, 1987.

RAMBO, B. O valor cultural das ciências naturais. Organom: Revista da Faculdade de Filosofia, Porto Alegre: Editora da UFRGS, ano 3, n. 2, 1959.

RAMBO, B. A fisionomia do Rio Grande do Sul. Porto Alegre: Livraria Selbach, 1956.

SCHMITZ, P. I. Balduíno Rambo, S. J., criador de talentos. Episteme, Porto Alegre: Instituto Latino Americano de Estudos Avançados/UFRGS, v. 2, n. 3, 1997.

MÜLLER, L.; ROBIN, S. História da Antropologia no Rio Grande do Sul. Porto Alegre, [s.d.]. Mimeografado.

WILLEMS, E. A aculturação dos alemães no Brasil: estudo antropológico dos imigrantes alemães e seus descendentes no Brasil. São Paulo: Companhia Editora Nacional, 1946.

\section{Entrevistas}

Pedro Ignácio Schmitz.

Artur Blásio Rambo.

José Joaquim Justiniano Proenza Brochado.

Sérgio Alves Teixeira.

Ruben George Oliven. 